Article

\title{
Reinforced Superhydrophobic Anti-Corrosion Epoxy Resin Coating by Fluorine-Silicon-Carbide Composites
}

\author{
Zhicai Zhang ${ }^{1}$, Nie Zhao ${ }^{1, *}$, Fugang $\mathrm{Qi}^{1}{ }^{1} * \mathbb{D}$, Biao Zhang ${ }^{1}$, Bin Liao ${ }^{2}$ and Xiaoping Ouyang ${ }^{1}$ \\ 1 School of Materials Science and Engineering, Xiangtan University, Xiangtan 411105, China; \\ ZC_Zhang99@foxmail.com (Z.Z.); xiaobiao_zhang@outlook.com (B.Z.); oyxp2003@aliyun.com (X.O.) \\ 2 College of Nuclear Science and Technology, Beijing Normal University, Beijing 100875, China; \\ liaobingz@bnu.edu.cn \\ * Correspondence: zhaonie@xtu.edu.cn (N.Z.); qifugang@xtu.edu.cn (F.Q.)
}

Received: 17 November 2020; Accepted: 15 December 2020; Published: 17 December 2020

\begin{abstract}
SiC}$ was modified by fluorine-containing organic substance $1 \mathrm{H}, 1 \mathrm{H}, 2 \mathrm{H}, 2 \mathrm{H}$-trifluoronoctyltriethoxysilane (FAS) to change its hydrophilicity from hydrophilic to superhydrophobic nanoparticles, and the optimum conditions for hydrophobicity were effectively explored. Then, different content of fluorine-modified $\mathrm{SiC}(\mathrm{F}-\mathrm{SiC})$ nanoparticles were added to the epoxy resin (EP) matrix to prepare composite coating samples. The results showed that the surface of $\mathrm{SiC}$ was modified by FAS to show superhydrophobicity, and the dispersion in EP was significantly improved. After adding $\mathrm{F}-\mathrm{SiC}$, the hydrophobicity, wear resistance and corrosion resistance of the coating were significantly improved. In addition, the corrosion resistance of the composite coating containing different contents of $\mathrm{F}-\mathrm{SiC}$ was analyzed through electrochemical and salt spray tests. The results showed that the corrosion resistance of the coating was the best when the addition amount was $3 \mathrm{wt} \%$. In general, the composite coating with $3 \mathrm{wt} \% \mathrm{~F}-\mathrm{SiC}$ had the best overall performance. Compared with the EP coating, the water contact angle of $3 \mathrm{wt} \% \mathrm{~F}-\mathrm{SiC} / \mathrm{EP}$ composite coating was increased by $62.9 \%$, the friction coefficient was reduced by $73.5 \%$, and the corrosion current was reduced by three orders of magnitude. This study provides a new idea for the development of ultra-wear-resistant and anti-fouling heavy-duty coatings.
\end{abstract}

Keywords: superhydrophobic; nanoparticles; composite coating; friction; corrosion

\section{Introduction}

Metal corrosion is one of the important factors causing huge economic losses around the world. The annual economic loss due to metal corrosion exceeds USD 100 billion, far exceeding the sum of natural disasters such as typhoons, floods and fires [1]. In addition, metal corrosion in engineering equipment may cause unsafe accidents due to the premature failure of structural materials [2]. Excessive heavy metal ions are released and diffused into water, soil and crops, causing serious pollution to the contemporary environment $[3,4]$. Therefore, it is very important to reduce the hazards of metal corrosion, and the research of adopting effective measures to slow down metal corrosion has become the focus of the research field in metal protection.

There are several ways to prevent metal corrosion for different engineering fields. At present, the main methods for metal protection include adding corrosion inhibitors [5], electrochemical protection methods [6], alloying treatment $[7,8]$, electroplating spraying $[9,10]$, and non-metallic coatings [11-13], etc. Corrosion inhibitors will accumulate adsorption film or insoluble substances on the metal surface, thereby changing the charge state and interface properties of the metal surface, accelerating the degree of polarization, forming a protective film, and minimizing corrosion micro-current. Three types of corrosion inhibitors (inorganic, organic and vapor phase) are developed 
according to the application requirement. However, because the corrosion inhibitor is toxic, excessive addition will cause severe pollution to the surrounding environment. For the alloying and electroplating spraying methods, the use in the construction environment is restricted by a complicated treating process. Non-metallic coatings have become the most popular metal protection method due to the advantages of simple construction, low cost and convenient cleaning. Among the non-metallic coatings, epoxy resin (EP) is the most widely used material in engineering fields. Although the epoxy resin has excellent corrosion resistance, high adhesion and a low price, the epoxy resin may contain hydrophilic groups such as $-\mathrm{OH},-\mathrm{CHOOH}$ and $-\mathrm{NH}_{2}$ to make the epoxy resin hydrophilic [14], and the liquids can maintain firm contact with the epoxy surface, thereby accelerating the corrosion processes. To solve these problems in epoxy resin coatings, a lot of research has been conducted to improve the mechanical property of epoxy resin and reduce the production of micropores. The composite of nanoparticles with epoxy resin has received widespread attention in the field of non-metallic coatings. The addition of nanomaterials such as $\mathrm{SiO}_{2}$ [15], $\mathrm{SiC}$ [16], $\mathrm{TiO}$ [17], $\mathrm{Al}_{2} \mathrm{O}_{3}$ [18], $\mathrm{ZnO}$ [19] graphene, graphene oxide, etc., can effectively increasing the anti-corrosion performance of epoxy resin coatings.

For some special application fields, such as marine cargo ships, warships, marine engineering, etc., the protective coatings require not only the corrosion resistance of the coating but also extremely high wear resistance and antifouling performance. It is well known that the $\mathrm{SiC}$ nanoparticle has excellent wear resistance, corrosion resistance, and excellent heat resistance [20-22], which can meet the requirements of super wear-resistant coatings [23]. In addition, the surface of $\mathrm{SiC}$ is rich in hydroxyl groups, and surface treatment can be an effective method to make it a hydrophobic material [24]. However, there are few reports on the use of $\mathrm{SiC}$ composites to enhance the performance of epoxy coatings. This is because the compatibility of $\mathrm{SiC}$ in epoxy resin is usually poor, and the higher surface energy of nano-sized $\mathrm{SiC}$ and strong hydrophilicity leads to severe particle agglomeration. Many methods have been tried to disperse SiC into EP. For example, samples containing 0.5, 1, 2 and $4 \mathrm{wt} \%$ of $\beta$-silicon carbide nanowhiskers and nanoparticles in epoxy resin were prepared using a high-intensity ultrasonic liquid processor and casting technique [25]. However, when the SiC fiber content increases, agglomeration occurs due to the interaction between the fillers. Therefore, a better dispersion method is worth studying. Kychkin studied the effect of ultra-fine silicon carbide powder on the performance of epoxy resin [26]. The study found that when adding $0.75 \mathrm{wt} \%$ silicon carbide, a $16 \%$ increase in flexural strength and a 5\% increase in compressive elastic modulus were observed. Archana Nigrawal studied the mechanical properties of epoxy resin/nano-SiC composites and found that the bending performance increased with the increase in $\mathrm{SiC}$ weight percentage, and the best bending performance was obtained when the weight percentage of $\mathrm{SiC}$ increased to $2 \mathrm{wt} \%$. However, when $3 \mathrm{wt} \%$ of SiC filler was added to EP, the bending performance of the composite material decreased instead [27]. Iijima studied the method of increasing the hydrophilic groups on the surface of $\mathrm{SiC}$ nanoparticles through reacting the unsaturated hydrocarbons with the azo radical initiator [28]. Huang introduced a new modifier, $1 \mathrm{H}, 1 \mathrm{H}, 2 \mathrm{H}, 2 \mathrm{H}$-perfluorooctyltriethoxysilane (FAS) for the covalent functionalization of graphene, thereby improving the dispersion of graphene in organic matter, which provided us with an idea for modifying $\mathrm{SiC}$ and improving the dispersion of $\mathrm{SiC}$ in the organic matter [29]. Shang developed a SiC surface modification method using 3-aminopropyltriethoxysilane (KH550) and 3-mercaptopropyltrimethoxysilane (KH590) as initial modifiers to improve the hydrophobic properties of $\mathrm{SiC}$ powder [30].

Based on the above studies, the composite material of superhydrophobic modification SiC with EP is a useful additive for improving anti-corrosion performance, and much research on hydrophobically modified nanoparticles filled with epoxy resin has been carried out [31,32], however, there are not many studies on superhydrophobic $\mathrm{SiC}$ particles filled with epoxy resin. In this work, a superhydrophobic $\mathrm{SiC}$ was synthesized by chemically grafting FAS onto the surface of $\mathrm{SiC}$, and then the superhydrophobic $\mathrm{SiC}$ was added to EP for producing SiC/EP composite material. Due to the grating of the organic molecule on the surface of $\mathrm{SiC}$, the compatibility of nano-SiC with EP was largely improved. The introduction of superhydrophobic $\mathrm{SiC}$ greatly improved the wear resistance, corrosion resistance and hydrophobicity 
of the composite coating. On this basis, the performance of the composite coating was optimized, the performance under different addition levels was studied, and the optimized ratio was obtained.

\section{Experimental}

\subsection{Materials}

Nano-SiC (40 nm) and 1H,1H,2H,2H-Tridecafluoro-n-octyltriethoxysilane ( $>97 \%)$ were purchased from Aladdin Industrial Co., Ltd. (Shanghai, China). EP (CYD 014, epoxy equivalent is 0.12) and its curing agent (P54, active hydrogen equivalent is 327.86) were purchased from Baling Chemical (Yueyang, China) Co. The thinners used in the experiment were xylene and n-butanol, which were purchased from Aladdin Industrial Co., Ltd. (Shanghai, China) in a volume ratio of 4:6. Ultrapure water (specific resistance $\geq 18 \mathrm{M} \Omega \cdot \mathrm{cm}$ ) was made in the laboratory, and absolute ethanol (analytical grade) and glacial acetic acid were purchased from Sinopharm Chemical Reagent Co., Ltd., China (Shanghai, China). Test substrates (Q235 steel sheets) were purchased from Biuged Laboratory Instruments Co., Ltd. (Guangzhou, China).

\subsection{Preparation of Superhydrophobic Nano-SiC}

The superhydrophobic modification of $\mathrm{SiC}$ was carried out by chemical grafting. Firstly, $0.4 \mathrm{~g}$ $\mathrm{SiC}$ was weighed and placed in a flask, then $100 \mathrm{~mL}$ of absolute ethanol was added and shaken for $30 \mathrm{~min}$. At the same time, stirring was started until the end of the experiment. Then, the $\mathrm{pH}$ of the solution was adjusted to $4 \sim 5$ by adding dropwise glacial acetic acid. A certain amount of FAS and $2 \mathrm{~mL}$ of water were added dropwise before the surface modification. Finally, F-SiC was prepared by heating in the water bath, stirring at $500 \mathrm{rpm}$ for $2 \mathrm{~h}$. The obtained superhydrophobic nano-SiC was washed and dried before adding to the epoxy coating.

\subsection{Preparation of Epoxy Composite Coating}

Before preparing the composite coating, the substrate was pretreated, including sanding, rust removal, oil removal and degreasing. The steps of preparing $\mathrm{F}-\mathrm{SiC} / \mathrm{EP}$ composite coating were as follows. First, a certain amount of F-SiC (1-5 wt \%) and EP were mixed and stirred for $12 \mathrm{~h}$. Then, the curing agent (P54) and diluent were added to the mixture. Subsequently, the thickness of the mixture was sprayed on the surface of the low-carbon steel sheet, and finally, the F-SiC/EP coating was cured at $80^{\circ} \mathrm{C}$ for $1 \mathrm{~h}$ to obtain a coating with a thickness of $60 \pm 5 \mu \mathrm{m}$.

\subsection{Characterization}

The morphology and physical structure were characterized by scanning electron microscope (SEM, ZEISS MERLIN Compact, Jena, Germany); The chemical structures of SiC before and after modification were characterized by Fourier-transform infrared spectroscopy (FTIR, Shanghai, China), X-ray diffraction (XRD, u1tima IV, Tokyo, Japan) and X-ray photoelectron spectroscopy (XPS, thermo Kalpha, Shanghai, China). The contact angle of water after hydrophobic modification was evaluated by a contact angle measuring instrument (DSA100, Hamburg, Germany), which uses the shape image analysis method: drop the droplet $(10 \mu \mathrm{L})$ on the surface of the solid sample, obtain the shape image of the droplet through the microscope lens and the camera, and then use digital image processing and some algorithms to calculate the contact angle of the droplet in the image. The wear resistance of the coating was evaluated by a friction and wear tester (UMT-2, Campbell, Camden, NJ, USA). In the wear resistance test, the friction ball was a 440-carbon steel ball, which was loaded with a force of $2 \mathrm{~N}$ in the vertical direction, and rubbed back and forth at the speed of $40 \mathrm{~mm} / \mathrm{s}$ in a stroke of $10 \mathrm{~mm}$. The salt spray resistance of the coating was tested in a neutral salt spray test chamber (BGD-887) according to the ISO 9227-2017 standard [33]. An electrochemical workstation (zahner PP211, Kronach, Germany) was used to detect the corrosion resistance of the coating. 


\section{Results}

\subsection{The Reaction Conditions for the Modification of SiC Powder by FAS}

The contact angle characterization has been often used as a relatively simple method for assessing the properties of surfaces. The water contact angle $\left(\theta<90^{\circ}\right.$ and $\left.\theta>90^{\circ}\right)$ can indicate whether the surface has 'hydrophilicity' or 'hydrophobicity', respectively [34]. In order to find out the best reaction conditions for the modification $\mathrm{SiC}$ by grated FAS, the reaction conditions such as the amount of FAS, reaction temperature and reaction time were studied.

Figure 1 shows the contact angle of $\mathrm{SiC}$ as a function of FAS amount and reaction temperature. The $\mathrm{SiC}$ particles before modification can be considered as hydrophilic due to a water contact angle of $31.9^{\circ}$ (Figure 1a). It is generally accepted that the SiC powder surface has an oxide film and the major functional group on the surface is probably the silanol group $(\mathrm{Si}-\mathrm{OH})$, which causes the hydrophilicity of $\mathrm{SiC}$ [24].
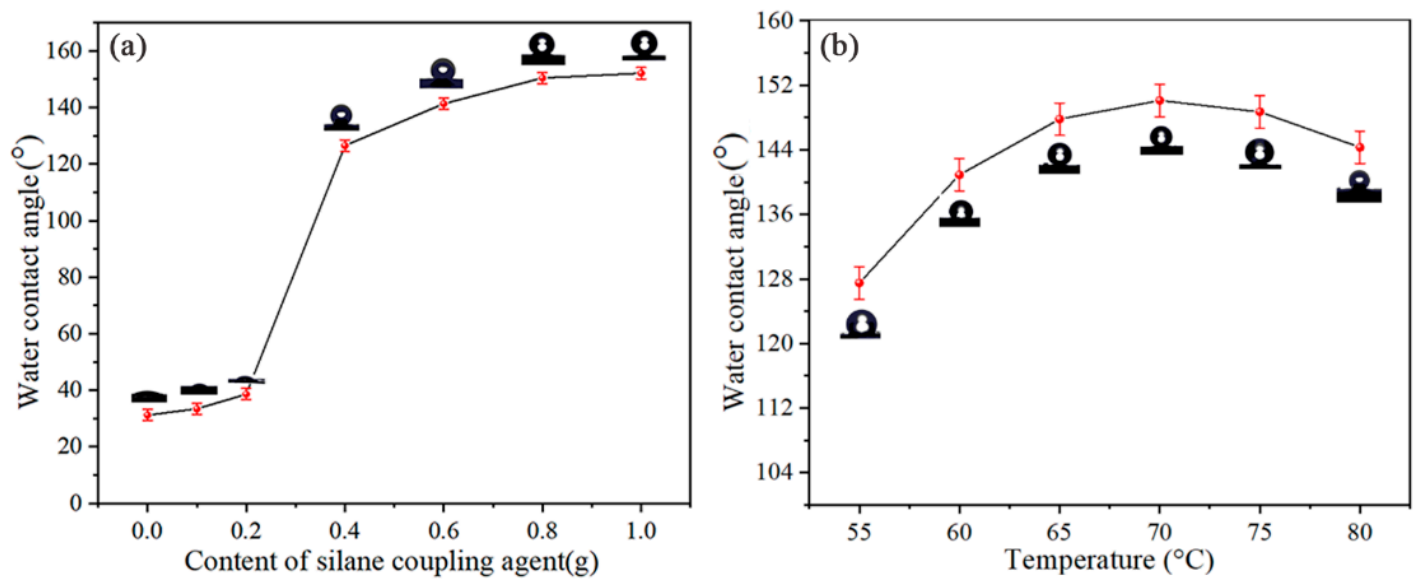

Figure 1. Water contact angle of $\mathrm{SiC}$ powder: (a) the effect of silane coupling agent amount, (b) the effect of reaction temperature.

After being modified by FAS, the hydrophobicity of SiC was effectively improved. It can be clearly observed that as the number of hydrophobic modifiers increases, the contact of $\mathrm{F}-\mathrm{SiC}$ does not increase significantly at first, but increases rapidly as the addition amount of silane coupling rises over $0.2 \mathrm{~g}$, and finally gradually tends to be stable. When the addition amount of FAS reaches $0.8 \mathrm{~g}$, the static water contact angle of $\mathrm{F}-\mathrm{SiC}$ exceeds $150^{\circ}$ (roll-off angle is $4.2^{\circ}$ ) and becomes superhydrophobic $\mathrm{SiC}$. The results show that the addition amount of the hydrophobic modifier FAS plays an important role in the modification of $\mathrm{SiC}$ powder. The reason may be that more and more silane alcohol groups will react with $-\mathrm{OH}$ on the $\mathrm{SiC}$ surface through alcohol hydroxyl groups when the silane is hydrolyzed continuously, so the contact angle is increased with the degree of grafting $[35,36]$.

The influence of different reaction temperature on $\mathrm{SiC}$ modification is investigated, as shown in Figure 1b. It can be seen that the contact angle first increases and then decreases as the reaction temperature increases. The maximum contact angle is obtained at $70{ }^{\circ} \mathrm{C}$. This is because the hydrolysis process of silane was accelerated by the increasing reaction temperature which could promote the condensation reaction of $-\mathrm{OH}$ on the $\mathrm{SiC}$ surface with hydrophobic silane. The basic reaction scheme is that the silane is firstly hydrolyzed to produce an alcoholic hydroxyl group, and then the $\mathrm{H}$ of the hydroxyl group reacts with the $-\mathrm{OH}$ on the $\mathrm{SiC}$ surface to form a chemical bond. However, when the temperature is higher than $70{ }^{\circ} \mathrm{C}$, the Brownian movement among $\mathrm{SiC}$ particles becomes so fierce to aggravate them, which reduces the extent of grafting. Moreover, as the temperature increases, the silane coupling agent will have a strong tendency to self-polymerize, then the graft coupling agent on the SiC surface may be depolymerized. Therefore, the contact angle decreases with the reduced degree of grafting [30,37,38]. 
In order to further analyze the grating degree of FAS addition on $\mathrm{SiC}$ surface, thermogravimetric analysis (TGA) tests were carried out on F-SiC with different addition amounts of FAS (0-0.8 g). As shown in Figure 2, the weight loss of the sample is divided into two stages. The first stage occurred in the range of $30-420^{\circ} \mathrm{C}$, which was related to the desorption of physically adsorbed water and unreacted silane in the nanoparticles. The second stage occurs in the temperature range of $420-660{ }^{\circ} \mathrm{C}$, which was mainly due to the degradation of long-chain organics grafted to the surface of SiC. Therefore, the weight loss ratio in stage 2 is the ratio of silane in the chemical reaction. When the content of FAS was $0.1 \mathrm{~g}$, the weight loss of the second stage was almost very low, which indicates that there were few grafted organics. However, when the content of FAS increased to $0.8 \mathrm{~g}$, the weight loss of the second stage increased sharply, indicating that the number of grafted organics was also increased. The quantity loss at each stage is shown in Table 1.

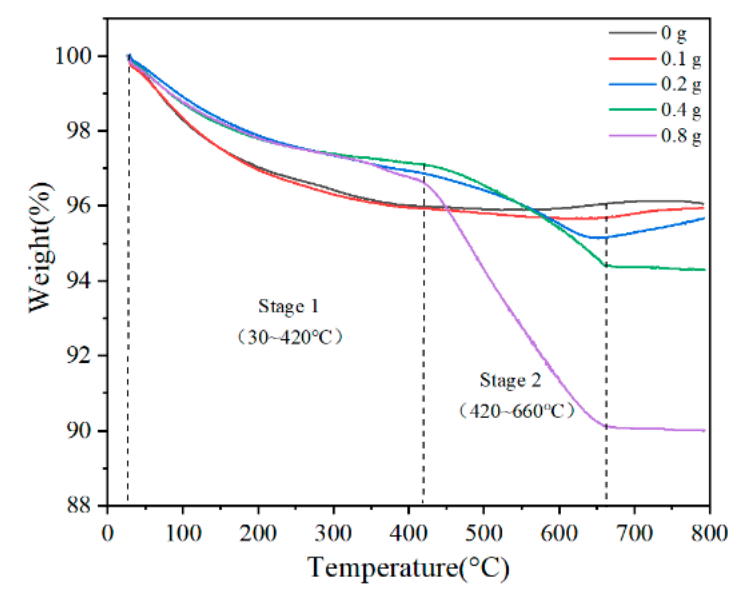

Figure 2. TGA curves of samples with different contents of FAS.

Table 1. The weight loss at different stage and total weight loss of different amount of FAS.

\begin{tabular}{cccc}
\hline Samples & Stage 1 Weight Loss (\%) & Stage $\mathbf{2}$ Weight Loss $(\mathbf{\%})$ & Total Weight Loss at $\mathbf{8 0 0}{ }^{\circ} \mathbf{C}(\%)$ \\
\hline $0 \mathrm{~g}$ & 4.02 & -0.09 & 3.93 \\
$0.1 \mathrm{~g}$ & 4.02 & 0.29 & 4.31 \\
$0.2 \mathrm{~g}$ & 3.14 & 1.71 & 4.35 \\
$0.4 \mathrm{~g}$ & 2.89 & 2.71 & 5.71 \\
$0.8 \mathrm{~g}$ & 3.39 & 6.49 & 10.01 \\
\hline
\end{tabular}

\subsection{The Structural Characterization of F-SiC Powder}

In this study, XRD was used to identify the structure of SiC before and after modification. Figure 3a is the XRD diagram of $\mathrm{SiC}$ before and after modification. It can be seen from the figure that the position and intensity of diffraction peaks before and after modification have not changed, and the positions of diffraction peaks are consistent with the previous literatures $[39,40]$. It should be noted that the SF peak is caused by stacking faults of $\mathrm{SiC}$ [41,42]. In addition, XPS is used to characterize the change of chemical valence before and after modification. Figure $3 \mathrm{~b}$ shows the XPS spectra of $\mathrm{SiC}$ and $\mathrm{F}-\mathrm{SiC}$. It can be seen from the figure that $\mathrm{SiC}$ mainly contains $\mathrm{Si}, \mathrm{C}$ and $\mathrm{O}$ elements without modification, while a strong $\mathrm{F}$ element peak was added after modification, which came from hydrophobic modifier FAS. Figure $3 \mathrm{c}$ shows the high-resolution spectra of $\mathrm{O} 1 \mathrm{~s}$ in $\mathrm{SiC}$. It is remarkable that the spectra of $\mathrm{O}$ $1 s$ are mainly divided into $\mathrm{Si-OH}$ and $\mathrm{H}-\mathrm{OH}$, respectively. The $\mathrm{Si}-\mathrm{OH}$ comes from the $-\mathrm{OH}$ on the surface of $\mathrm{SiC}$, which is consistent with the reports in the literature [24]. $\mathrm{H}-\mathrm{OH}$ is considered as the introduction of adsorbed water on the $\mathrm{SiC}$ surface. Figure $3 \mathrm{~d}$ shows the high-resolution spectra of $\mathrm{Si}$ $2 s$ in $\mathrm{F}-\mathrm{SiC}$. The spectra of $\mathrm{Si} 2 s$ are mainly fitting to three peaks, namely $\mathrm{Si}-\mathrm{O}-\mathrm{Si}, \mathrm{Si}-\mathrm{C}$ and $\mathrm{Si}-\mathrm{O}-\mathrm{C}$. Among them, the $\mathrm{Si}-\mathrm{C}$ peak is attributed to the $\mathrm{SiC}$ particles. The alcoholic hydroxyl groups of the hydrolyzed FAS and the hydroxyl groups on the surface of the $\mathrm{SiC}$ undergo a dehydration reaction 
to form Si-O-Si. This result can be mutually verified with Figure 4, indicating the grafting process success. Finally, Si-O-C comes from the unhydrolyzed groups in FAS. The above discussion shows that FAS was successfully grafted on the surface of $\mathrm{SiC}$.
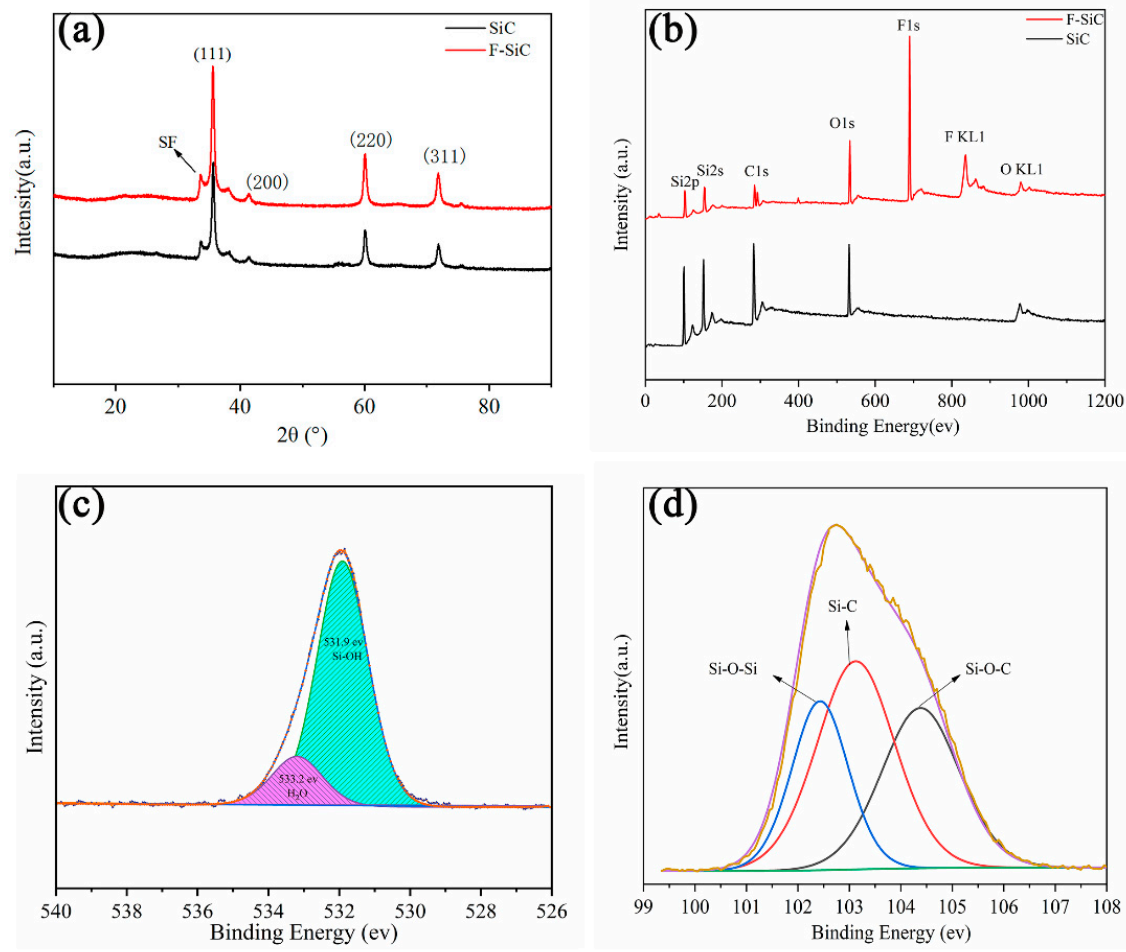

Figure 3. X-ray analysis: (a) XRD spectra of SiC before and after modification; (b) XPS spectra of SiC before and after modification; (c) high-resolution XPS spectra of $\mathrm{O} 1 s$ in SiC; (d) high-resolution XPS spectra of Si in F-SiC.

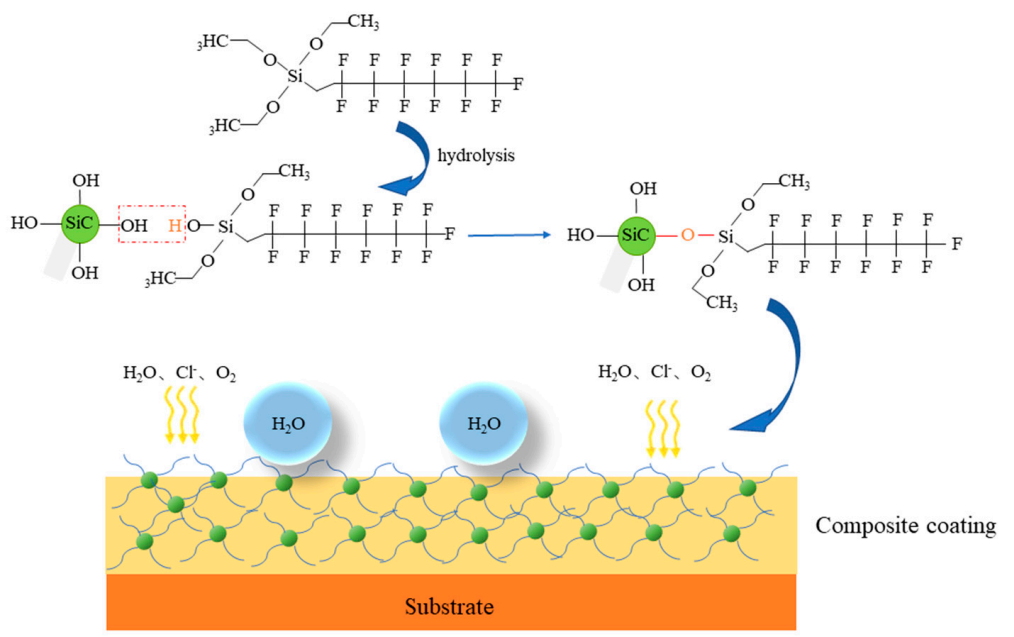

Figure 4. Experimental procedures of fabricating $\mathrm{F}-\mathrm{SiC}$ and composite coating.

To verify the above analysis, the FTIR spectra are used to identify functional groups and show vibrational modes of the bonds on the $\mathrm{SiC}$ surface. Figure 5 shows the FTIR spectra before and after modification with FAS. The peaks at 1062 and $873 \mathrm{~cm}^{-1}$ are characteristic peaks of SiC. The peaks at 2846 and $2911 \mathrm{~cm}^{-1}$ are mainly the stretching vibrations of $\mathrm{C}-\mathrm{H}$ [43], which are primarily related to the methylene introduced by FAS modification. In addition, the absorption peak at $1135 \mathrm{~cm}^{-1}$ belongs to the stretching vibration of $\mathrm{Si}-\mathrm{O}-\mathrm{Si}$ [35], and the tensile vibration peak of $\mathrm{C}-\mathrm{F}$ appears at 
$1211 \mathrm{~cm}^{-1}$ [44], which indicates that FAS has been successfully chemically bonded to SiC powder in the form of covalent bonding. After modification, the $-\mathrm{OH}$ flexural vibration peak at $1390 \mathrm{~cm}^{-1}$ is significantly weakened, indicating that $-\mathrm{OH}$ was consumed by FAS. Combining with the previous expression, it can be seen that the reaction between FAS and $\mathrm{SiC}$ is chemical bonding rather than simple physical adsorption.

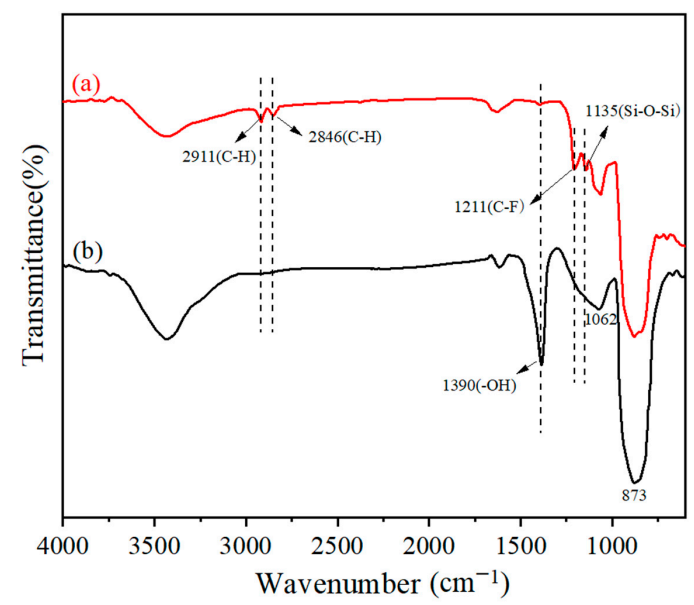

Figure 5. FTIR spectra of the samples: (a) F-SiC, (b) SiC.

\subsection{The Structural Characterization of the Coating System}

The hydrophobicity of the composite coating with different content of F-SiC is characterized by the contact angle, and the test results are shown in Figure 6. It can be seen from Figure 6 that the contact angle of the coating is less than $90^{\circ}$ without the addition of F-SiC. The contact angle of the coating increases significantly with the addition of F-SiC. A composite coating with superhydrophobic property was obtained as the added $\mathrm{F}-\mathrm{SiC}$ reached $5 \mathrm{wt} \%$, where a static water contact angle of $150.1^{\circ}$ was achieved (roll-off angle is $5.5^{\circ}$ ).

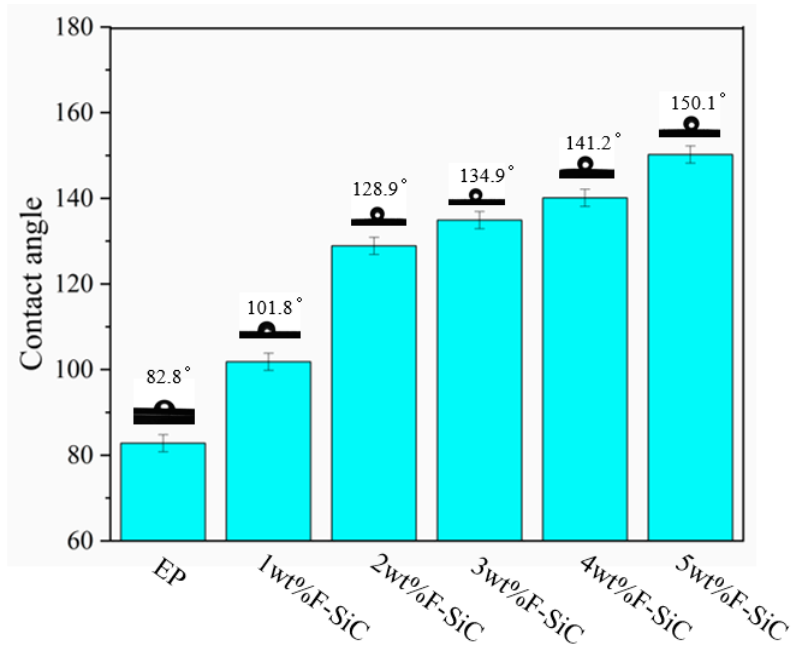

Figure 6. Contact angle of composite coating with different content of F-SiC.

Moreover, the wear resistance of EP composite coating will be greatly improved due to the super wear-resistance of $\mathrm{SiC}$. The friction coefficients of the composite coating with different tested $\mathrm{F}-\mathrm{SiC}$ samples are shown in Figure 7. It is well known that the epoxy resin is commonly hard and brittle, and has a low fracture energy and poor wear resistance. During the friction process, EP will undergo an oxidation reaction. The surface macromolecular chains deform under the action of shear stress, and the 
chemical and hydrogen bonds within and between the molecular chains are broken [45]. Therefore, the friction coefficient of EP is relatively high, and the friction process is very unstable. The friction coefficient of the composite coating is significantly reduced after adding $\mathrm{F}-\mathrm{SiC}$ nanoparticles to $\mathrm{EP}$, which can be attributed to two reasons [43]. On the one hand, nanofillers use their own hardness to limit the movement of the surrounding epoxy macromolecules and polymer chains and play a supporting role under load. On the other hand, the properties and geometry of the superhydrophobic surface and surface-liquid interaction will affect the friction of the coating surface [46]. The superhydrophobic wetting state converts the surface into quasi-frictionless due to the very small solid-liquid contact area, resulting from the hydrophobic surface chemistry and laboratory micro-nanoroughening. It is worth noting that although the friction coefficient of the coating decreases with the increase in $\mathrm{F}-\mathrm{SiC}$ content, when the amount of addition exceeds $3 \mathrm{wt} \%$, instability appears in the middle and later stages of coating friction (Figure 7a). The average friction coefficient of each sample is shown in Figure $7 \mathrm{~b}$. As the content of $\mathrm{F}-\mathrm{SiC}$ increases, the average friction coefficient decreases sharply. When the content reaches $3 \mathrm{wt} \%$, the friction coefficient is very low, and the subsequent increase has little effect on the reduction in the friction coefficient.

(a)

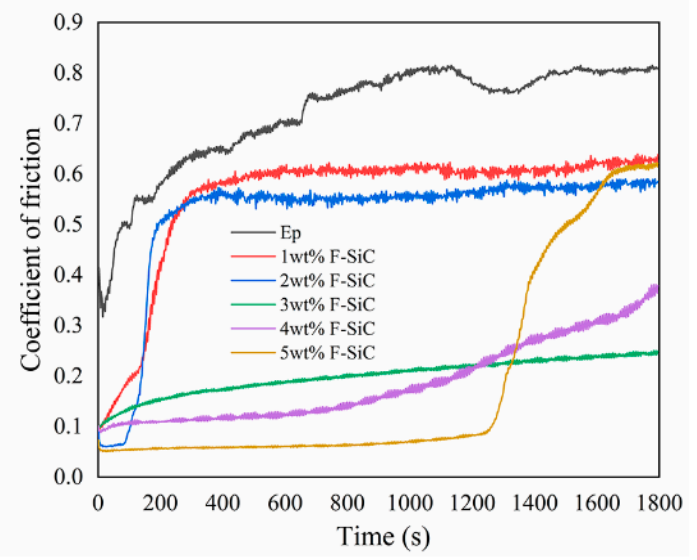

(b)

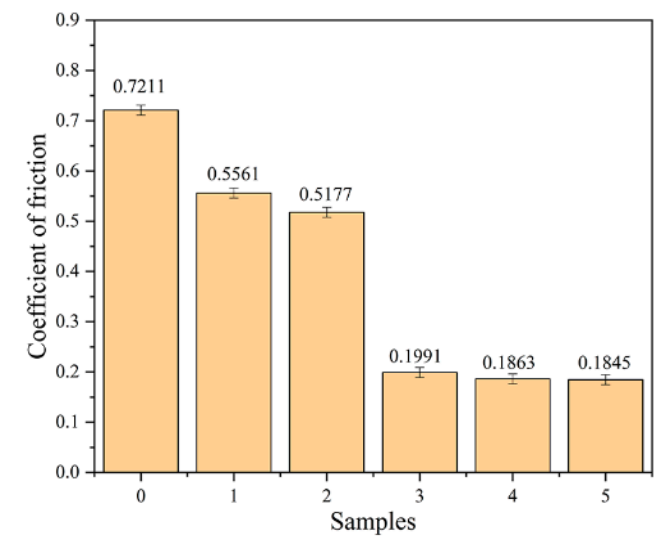

Figure 7. (a) Friction coefficient versus time, and (b) average friction coefficient of average friction coefficient of different F-SiC addition (0-5 wt \%).

The microstructures and morphologies of EP, $1 \mathrm{wt} \% \mathrm{~F}-\mathrm{SiC} / \mathrm{EP}, 3 \mathrm{wt} \% \mathrm{~F}-\mathrm{SiC} / \mathrm{EP}, 5 \mathrm{wt} \% \mathrm{~F}-\mathrm{SiC} / \mathrm{EP}$ were studied by SEM as shown in Figure 8. It can be seen from Figure 8a that the fracture surface of EP exhibits very smooth characteristics. The surface is relatively smooth without obvious defects, indicating brittle fracture and low fracture toughness [47,48], and due to the volatilization of the thinner, there are many steam holes in the coating.

When nano fillers with different contents are dispersed in epoxy resin, the fracture surface morphology of epoxy resin changes greatly. The SEM image of the 1 wt \% F-SiC/EP composite coating (Figure 8b) shows more obvious cracks than the pure EP coating (Figure 8a), and the breaking cracks caused by different addition contents are also different. When a small amount of $\mathrm{F}-\mathrm{SiC}$ is added, the cracks are less and show a streak shape; when the amount of addition is large, the cracks increase rapidly and appear lamellar, which is mainly due to the existence of F-SiC interfering with the directional fracture mode and inhibiting the crack growth [14]. In Figure 8d, it can be seen that the modified nano-SiC particles are more evenly distributed in the resin without agglomeration and have good dispersibility. However, When the F-SiC content increases to $5 \mathrm{wt} \%$, the volume ratio of $\mathrm{SiC}$ powder to EP is very large, resulting in SiC content which is too high. These can be seen from the SEM images (Figure 8e,f). 


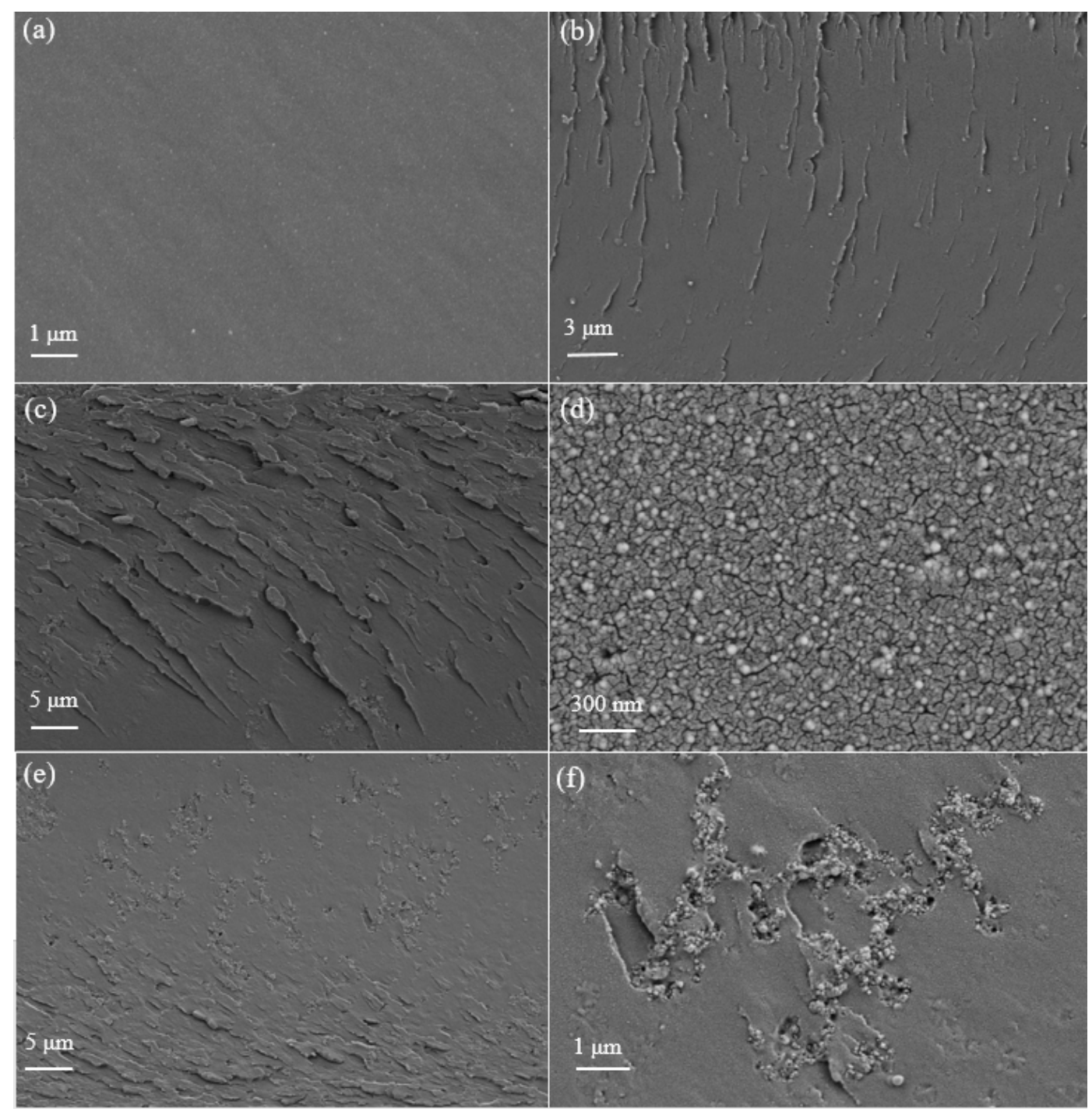

Figure 8. The fracture surface of the nanocomposite coatings: (a) epoxy resin (EP); (b) 1 wt \% F-SiC/EP, (c) 3 wt \% F-SiC/EP; (d) microscopic enlargement of 3 wt \% F-SiC/EP; (e) 5 wt \% F-SiC/EP; (f) microscopic enlargement of 5 wt \% F-SiC/EP.

\subsection{Corrosion Inhibitive Performance of Composite Coatings}

The electrochemical test is used to estimate the corrosion inhibitive performance of composite coatings as shown in Figure 9a. The corrosion inhibition effect of nanoparticles is analyzed by a potential polarization experiment. The polarization curve of the coating after being immersed in $3.5 \mathrm{wt} \% \mathrm{NaCl}$ solution for $24 \mathrm{~h}$ is shown in Figure $9 \mathrm{~b}$. The electrochemical parameters include corrosion current density $\left(i_{\text {corr }}\right)$, corrosion potential $\left(E_{\text {corr }}\right)$, anode $\left(\beta_{\mathrm{a}}\right)$ and cathode $\left(\beta_{\mathrm{c}}\right)$. A Tafel slope is shown in Table 2 . The corrosion current density $\left(i_{\text {corr }}\right)$ can be obtained from the Tafel diagram by extrapolating the straight-line part $\left(E_{\text {corr }}\right)$ of the corrosion potential curve [49].

It can be seen that the pure EP coating has relatively negative corrosion potential and high corrosion current, but when adding a certain amount of $\mathrm{F}-\mathrm{SiC}$, the corrosion potential of the composite coating moves to the positive potential direction, and the corrosion current decreases. When the content of $\mathrm{F}-\mathrm{SiC}$ is $3-4 \mathrm{wt} \%$, the corrosion potential of the composite coating reaches the maximum value, and the corrosion current is extremely low. As shown in Table 2, the corrosion current of the composite coating added with $\mathrm{F}-\mathrm{SiC}$ is $2-3$ orders of magnitude lower than that of the pure EP coating, and the corrosion resistance of the coating is greatly improved. 

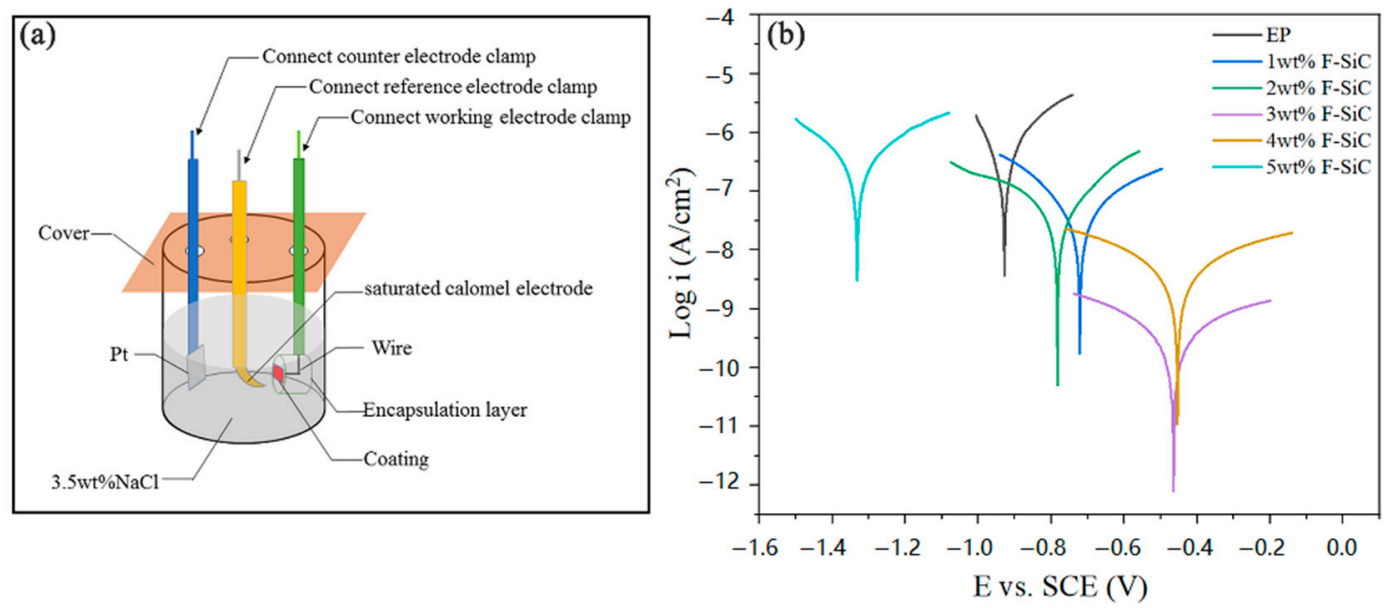

Figure 9. Electrochemical test: (a) electrochemical test model; (b) Tafel diagrams with different coatings.

Table 2. The electrochemical corrosion parameters derived by potentiodynamic polarization test.

\begin{tabular}{ccccc}
\hline Samples & $E_{\text {corr }}(\mathbf{V}$ vs. SCE $)$ & $i_{\text {corr }}\left(\mathrm{A} / \mathbf{c m}^{2}\right)$ & $\beta_{\mathbf{a}}(\mathbf{V} / \mathbf{d e c})$ & $-\beta_{\mathrm{c}}(\mathrm{V} / \mathbf{d e c})$ \\
\hline Blank solution & -0.928 & $1.524 \times 10^{-7}$ & 0.066 & 0.071 \\
1 wt $\% \mathrm{~F}-\mathrm{SiC} / \mathrm{EP}$ & -0.722 & $1.754 \times 10^{-8}$ & 0.118 & 0.111 \\
$2 \mathrm{wt} \% \mathrm{~F}-\mathrm{SiC} / \mathrm{EP}$ & -0.786 & $2.667 \times 10^{-8}$ & 0.155 & 0.155 \\
$3 \mathrm{wt} \% \mathrm{~F}-\mathrm{SiC} / \mathrm{EP}$ & -0.468 & $1.837 \times 10^{-10}$ & 0.375 & 0.417 \\
$4 \mathrm{wt} \% \mathrm{~F}-\mathrm{SiC} / \mathrm{EP}$ & -0.455 & $1.751 \times 10^{-9}$ & 0.171 & 0.162 \\
5 wt $\% \mathrm{~F}-\mathrm{SiC} / \mathrm{EP}$ & -1.332 & $1.770 \times 10^{-7}$ & 0.154 & 0.139 \\
\hline
\end{tabular}

Electrochemical impedance spectroscopy (EIS) is further used to evaluate and compare the anti-corrosion performance of composite coatings. Figure 10 shows the Nyquist diagrams and the corresponding Bode diagrams and its Effective circuit model of pure EP and F-SiC/EP coatings with different contents (1-5 wt \%) after immersion in 3.5\% NaCl aqueous solution for one day and five days. In the equivalent circuit, the parameters of $R_{\mathrm{s}}, R_{\mathrm{c}}, Q_{\mathrm{c}}, Q_{\mathrm{dl}}$ and $R_{\mathrm{ct}}$ correspond to solution resistance, coating resistance, coating capacitance, electric double-layer capacitance, and charge transfer resistance, respectively $[50,51]$. Generally, the impedance modulus at the lowest frequency $\left(Z_{f}=0.01 \mathrm{~Hz}\right)$ in the Bode plot can be defined as a parameter for the barrier properties of the coating [52]. After one day of immersion, the Nyquist diagrams all have only one semi-circular arc and only one time constant, and they are all in the early stage of corrosion, as shown in Figure 10a. From Figure 10b, it can be seen that the $Z_{\mathrm{f}}=0.01 \mathrm{~Hz}$ value of pure epoxy resin is $2.799 \times 10^{6} \Omega \cdot \mathrm{cm}^{2}$, which is much lower than the $Z_{\mathrm{f}}=0.01 \mathrm{~Hz}$ value $\left(1.38^{6} \times 10^{9} \Omega \cdot \mathrm{cm}^{2}\right)$ added with $3 \mathrm{wt} \% \mathrm{~F}-\mathrm{SiC} / \mathrm{EP}$ composite coating.

After five days of immersion, the $Z_{\mathrm{f}}=0.01 \mathrm{~Hz}$ value of the coating has a certain degree of decrease. The $Z_{\mathrm{f}}=0.01 \mathrm{~Hz}$ value of the pure EP coating drops to $3.551 \times 10^{5} \Omega \cdot \mathrm{cm}^{2}$, and a second arc appears in the Nyquist diagram (Figure 10c), indicating that coating enters the middle stage of corrosion, while the $3 \mathrm{wt} \% \mathrm{~F}-\mathrm{SiC} / \mathrm{EP}$ coating still has the highest $Z_{\mathrm{f}}=0.01 \mathrm{~Hz}$ value $\left(3.106 \times 10^{5} \Omega \cdot \mathrm{cm}^{2}\right)$, and its Nyquist diagram shows that the coating is still in the early stage of corrosion.

In order to more intuitively reflect the difference between the pure EP coating and the $3 \mathrm{wt} \%$ $\mathrm{F}-\mathrm{SiC} / \mathrm{EP}$ coating, EIS measurements with different immersion times are performed, as shown in Figure 11. The Nyquist diagram of EP coating at two days (Figure 11a) shows the second arc, which indicates that the coating enters the middle corrosion stage the next day, while the $3 \mathrm{wt} \%$ $\mathrm{F}-\mathrm{SiC} / \mathrm{EP}$ coating (Figure 11c) enters the intermediate corrosion stage on the 10th day. Moreover, it can be seen from the Bode diagram that the $Z_{\mathrm{f}}=0.01 \mathrm{~Hz}$ of pure EP coating (Figure 11b) decreases rapidly, while the $Z_{\mathrm{f}}=0.01 \mathrm{~Hz}$ of $3 \mathrm{wt} \% \mathrm{~F}-\mathrm{SiC} / \mathrm{EP}$ coating (Figure 11d) maintains a relatively stable value. Detailed electrochemical corrosion data are given in Table 3. 

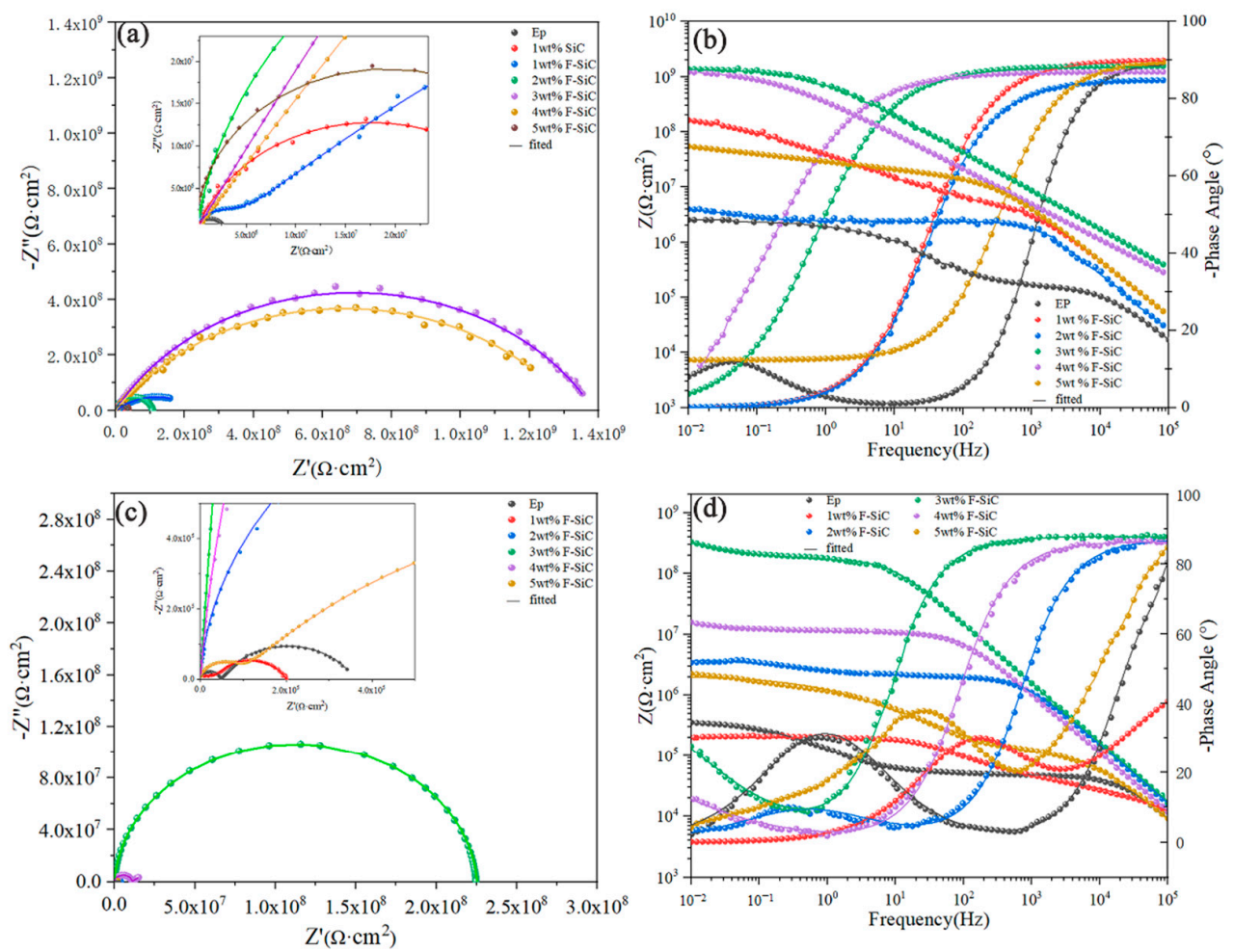

(e)

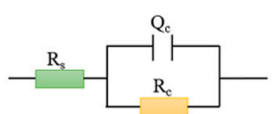

(f)

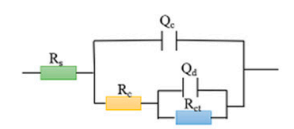

Figure 10. The Nyquist diagram (a) and bode diagram (b) of different coatings immersed for $12 \mathrm{~h}$; the Nyquist diagram (c) and bode diagram (d) of different coatings immersed for $48 \mathrm{~h}$; the Fitting circuit in presoaking stage (e) and medium stage (f).
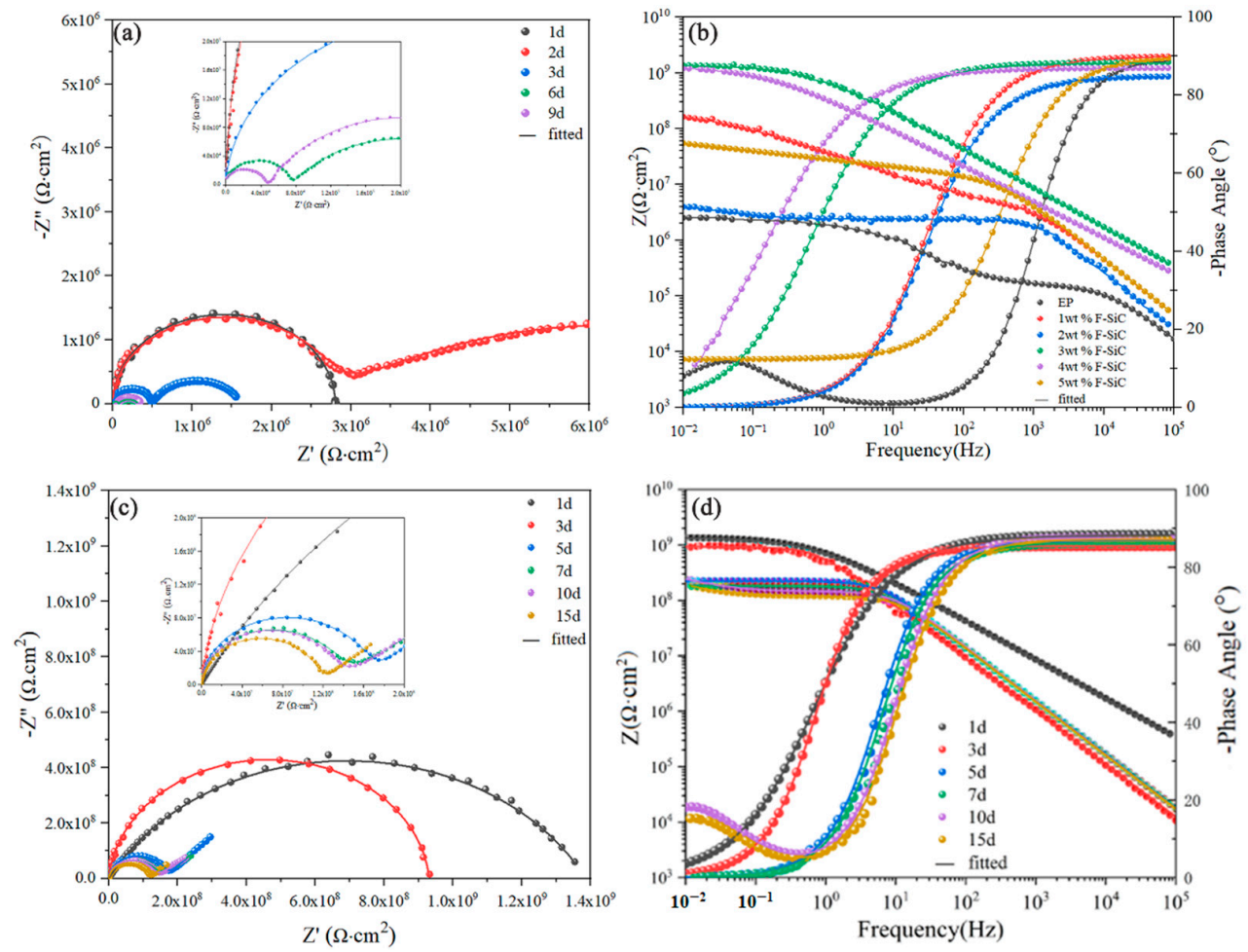

Figure 11. Nyquist and Bode diagram of $(\mathbf{a}, \mathbf{b})$ neat epoxy, (c,d) 3 wt \% F-SiC/epoxy. 
Table 3. Electrochemical impedance spectroscopy data of neat epoxy and nanocomposite coatings.

\begin{tabular}{|c|c|c|c|c|c|c|c|}
\hline \multirow{2}{*}{ Samples } & \multirow{2}{*}{ Time } & \multicolumn{2}{|l|}{$Q_{\mathrm{c}}$} & \multirow{2}{*}{$R_{\mathrm{c}}\left(\Omega \cdot \mathrm{cm}^{2}\right)$} & \multicolumn{2}{|l|}{$Q_{\mathrm{d}}$} & \multirow{2}{*}{$R_{\mathrm{ct}}\left(\Omega \cdot \mathrm{cm}^{2}\right)$} \\
\hline & & $Y_{0}\left(\Omega^{-1} \mathrm{~cm}^{-2} \mathrm{~s}^{n}\right)$ & $n$ & & $Y_{0}\left(\Omega^{-1} \mathrm{~cm}^{-2} \mathrm{~s}^{n}\right)$ & $n$ & \\
\hline \multirow{5}{*}{ EP } & $1 \mathrm{~d}$ & $6.243 \times 10^{-11}$ & 0.998 & $2.799 \times 10^{6}$ & - & - & - \\
\hline & $2 \mathrm{~d}$ & $1.194 \times 10^{-10}$ & 0.9931 & $2.593 \times 10^{6}$ & $2.090 \times 10^{-7}$ & 0.4094 & $7.35 \times 10^{6}$ \\
\hline & $3 \mathrm{~d}$ & $1.757 \times 10^{-10}$ & 0.9655 & $4.900 \times 10^{5}$ & $6.899 \times 10^{-7}$ & 0.7169 & $1.137 \times 10^{6}$ \\
\hline & $4 \mathrm{~d}$ & $4.486 \times 10^{-10}$ & 0.929 & $7.531 \times 10^{4}$ & $2.418 \times 10^{-7}$ & 0.6027 & $2.493 \times 10^{5}$ \\
\hline & $5 \mathrm{~d}$ & $3.159 \times 10^{-10}$ & 0.953 & $4.788 \times 10^{4}$ & $2.592 \times 10^{-7}$ & 0.689 & $3.126 \times 10^{5}$ \\
\hline \multirow{6}{*}{$3 \mathrm{wt} \% \mathrm{~F}-\mathrm{SiC}$} & $1 \mathrm{~d}$ & $2.558 \times 10^{-10}$ & 0.963 & $1.386 \times 10^{9}$ & - & - & - \\
\hline & $3 \mathrm{~d}$ & $2.494 \times 10^{-10}$ & 0.9494 & $9.307 \times 10^{8}$ & - & - & - \\
\hline & $5 \mathrm{~d}$ & $1.378 \times 10^{-10}$ & 0.9654 & $2.247 \times 10^{8}$ & - & - & - \\
\hline & $7 \mathrm{~d}$ & $1.522 \times 10^{-10}$ & 0.9584 & $1.821 \times 10^{8}$ & - & - & - \\
\hline & $10 \mathrm{~d}$ & $1.252 \times 10^{-10}$ & 0.9794 & $1.431 \times 10^{8}$ & $4.826 \times 10^{-8}$ & 0.7496 & $2.360 \times 10^{8}$ \\
\hline & $15 \mathrm{~d}$ & $1.378 \times 10^{-10}$ & 0.9714 & $1.202 \times 10^{8}$ & $7.424 \times 10^{-8}$ & 0.7802 & $1.386 \times 10^{8}$ \\
\hline
\end{tabular}

\subsection{Salt Spray Corrosion Resistance}

A salt spray test was performed to further explore the performance of the composite coating, as shown in Figure 12. Before the experiment, scratches should be made on the surface of the coating to facilitate observation of corrosion. Figure 12b shows different coating samples (EP, 1-5 wt \% F-SiC/EP) after $240 \mathrm{~h}$ of salt spray test. It can be seen that after $240 \mathrm{~h}$ of salt spray test, the pure EP coating and the coating with low $\mathrm{F}-\mathrm{SiC}$ content have many blisters on both sides of the scratch, and the corrosion depth is considerably high. Within the range of $2 \mathrm{~mm}$, pitting corrosion will occur in the area not scratched. The pitting corrosion and blistering of the $2-3 \mathrm{wt} \% \mathrm{~F}-\mathrm{SiC} / \mathrm{EP}$ composite coating are improved, but when the $\mathrm{F}-\mathrm{SiC}$ content is further increased, the corrosion range near the scratch becomes larger and the rust phenomenon becomes serious. The results show that the shielding performance of the coating can be enhanced by adding an appropriate amount of $\mathrm{F}-\mathrm{SiC}$ composite. In addition, the F-SiC/EP composite coating with about $3 \mathrm{wt} \%$ has the best anti-corrosion performance, which is consistent with the results of EIS.

(a)

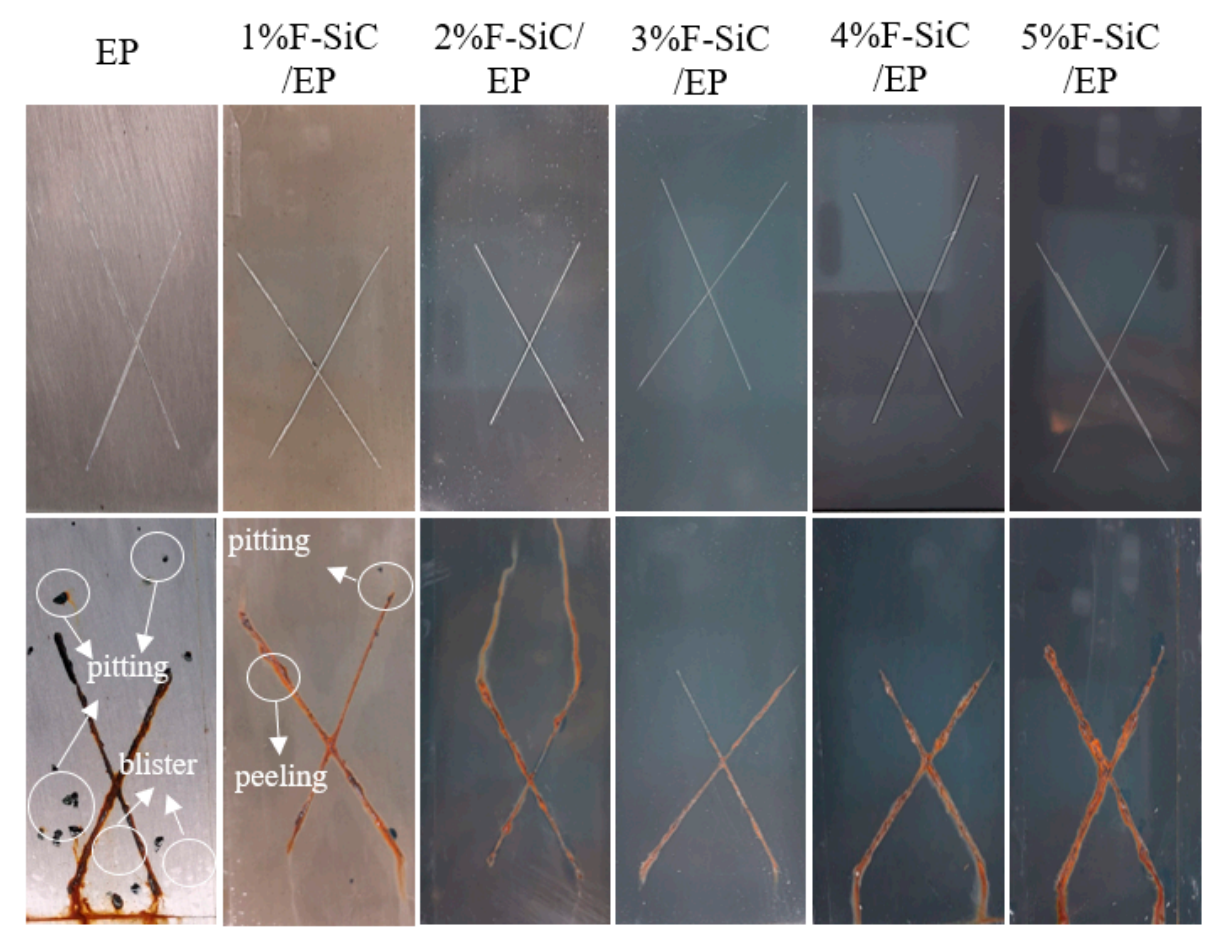

Figure 12. Photographs of different coating salt spray tests: (a) before the salt spray test; (b) $240 \mathrm{~h}$ after the salt spray test.

In this work, good results have been obtained, and we have also compared the anti-corrosion performance of similar materials in the literature. The comparison of the results is shown in Table 4. 
Table 4. Comparison of the anti-corrosion performance of similar materials.

\begin{tabular}{|c|c|c|c|c|c|}
\hline Samples & $\begin{array}{c}\text { Addition } \\
\text { Amount }\end{array}$ & $\begin{array}{l}\text { Water Contact } \\
\text { Angle }\end{array}$ & Abrasion Tests & $\begin{array}{c}\text { Electrochemical } \\
\text { Impedance Spectroscopy }\end{array}$ & $\begin{array}{c}\text { Salt Spray } \\
\text { Test }\end{array}$ \\
\hline $\mathrm{F}-\mathrm{SiC} / \mathrm{EP}$ & 3 wt $\%$ & $134.9^{\circ}$ & $\begin{array}{l}\text { The friction coefficient was } \\
\text { reduced by } 73.5 \%\end{array}$ & $1.386 \times 10^{9} \Omega \cdot \mathrm{cm}^{2}$ & $240 \mathrm{~h}$ \\
\hline $\mathrm{SiO}_{2} / \mathrm{EP}-\mathrm{ODA}$ [32] & $>35$ wt $\%$ & $153.6^{\circ}$ & $\begin{array}{c}\text { The coatings have considerably } \\
\text { stable abrasion resistance. }\end{array}$ & - & - \\
\hline $\mathrm{SiO}_{2} / \mathrm{EP}[53]$ & 40 wt $\%$ & $156^{\circ}$ & The retention ratio was about $78 \%$ & - & - \\
\hline OMSEP/EP [54] & $3 w t \%$ & $101^{\circ}$ & - & about $10^{9} \Omega \cdot \mathrm{cm}^{2}$ & $240 \mathrm{~h}$ \\
\hline MEC [55] & $9.09 \mathrm{wt} \%$ & $95.9^{\circ}$ & - & $5.25 \times 10^{5} \Omega \cdot \mathrm{cm}^{2}$ & $336 \mathrm{~h}$ \\
\hline
\end{tabular}

\section{Conclusions}

First of all, the hydrophilic surface of $\mathrm{SiC}$ was modified into hydrophobic material by chemical grafting, and the contact angle of $\mathrm{F}-\mathrm{SiC}$ was greatly improved. Next, filling $\mathrm{F}-\mathrm{SiC}$ into EP can significantly improve the hydrophobicity, wear resistance and corrosion resistance of the coating. As the amount of F-SiC added increases, the coating gradually changes from a hydrophilic coating to a superhydrophobic coating. When $3 \mathrm{wt} \% \mathrm{~F}-\mathrm{SiC}$ was added, the coating had the best tribological properties. Finally, the coatings with different proportions were tested, and it was found that the coating containing $3 \mathrm{wt} \% \mathrm{~F}-\mathrm{SiC}$ had the best improvement in the overall performance.

Author Contributions: Conceptualization, X.O.; investigation, B.L.; methodology, Z.Z.; writing—original draft, Z.Z. and Z.Z.; writing-review and editing, F.Q., N.Z., and B.Z. All authors have read and agreed to the published version of the manuscript.

Funding: This research was funded by National Natural Science Foundation of China (51701172); Educational Commission of Hunan Province of China (20B579); Hunan Provincial Natural Science Foundation of China (2020JJ4086, 2018JJ4053), Scientific Research Fund of Hunan Provincial Education Department (19B570), the China Postdoctoral Science Foundation (2017M622595, 2018M632977), Major Program of Hunan Province (2018RS3091).

Conflicts of Interest: The authors declare no conflict of interest.

\section{References}

1. Chauhan, D.S.; Quraishi, M.A.; Ansari, K.R.; Saleh, T.A. Graphene and graphene oxide as new class of materials for corrosion control and protection: Present status and future scenario. Prog. Org. Coat. 2020, 147, 105741. [CrossRef]

2. Sun, P.; Wang, Z.; Lu, Y.; Shen, S.; Yang, R.; Xue, A.; Parker, T.; Wang, J.; Wang, Q. Analysis of the corrosion failure of a semiconductor polycrystalline distillation column. Process Saf. Environ. Prot. 2020, 135, 244-256. [CrossRef]

3. Bradl, H.B. Adsorption of heavy metal ions on soils and soils constituents. J. Colloid Interface Sci. 2004, 277, 1-18. [CrossRef] [PubMed]

4. Chajduk, E.; Bojanowska-Czajka, A. Corrosion mitigation in coolant systems in nuclear power plants. Prog. Nucl. Energy 2016, 88, 1-9. [CrossRef]

5. Tang, Z. A review of corrosion inhibitors for rust preventative fluids. Curr. Opin. Solid State Mater. Sci. 2019, 23, 100759. [CrossRef]

6. Grundmeier, G.; Schmidt, W.; Stratmann, M. Corrosion protection by organic coatings: Electrochemical mechanism and novel methods of investigation. Electrochim. Acta 2000, 45, 2515-2533. [CrossRef]

7. Li, M.; Hu, P.; Zhang, Y.; Chang, Y. Enhancing performance of the CuCrZrTiV alloys through increasing recrystallization resistance and two-step thermomechanical treatments. J. Nucl. Mater. 2021, 543, 152482. [CrossRef]

8. Zhang, J.J; Liu, J.C.; Liao, H.M.; Zeng, M.; Ma, S. A review on relationship between morphology of boride of Fe-B alloys and the wear/corrosion resistant properties and mechanisms. Mater. Today Proc. 2020, 8, 6308-6320. [CrossRef]

9. Fallah, P.; Rajagopalan, S.; McDonald, A.; Yue, S. Development of hybrid metallic coatings on carbon fiber-reinforced polymers (CFRPs) by cold spray deposition of copper-assisted copper electroplating process. Surf. Coat. Technol. 2020, 400, 126231. [CrossRef] 
10. Lim, J.; Lee, C. The rf-power dependences of the deposition rate, the hardness and the corrosion-resistance of the chromium nitride film deposited by using a dual ion beam sputtering system. Mater. Chem. Phys. 2006, 95, 164-168. [CrossRef]

11. Olajire, A.A. Recent advances on organic coating system technologies for corrosion protection of offshore metallic structures. J. Mol. Liq. 2018, 269, 572-606. [CrossRef]

12. Han, Y.H.; Taylor, A.; Knowles, K.M. Scratch resistance and adherence of novel organic-inorganic hybrid coatings on metallic and non-metallic substrates. Surf. Coat. Technol. 2009, 203, 2871-2877. [CrossRef]

13. Deering, J.; Clifford, A.; D’Elia, A.; Zhitomirsky, I.; Grandfield, K. Composite dip coating improves biocompatibility of porous metallic scaffolds. Mater. Lett. 2020, 274, 128057. [CrossRef]

14. Jin, F.L.; Li, X.; Park, S.J. Synthesis and application of epoxy resins: A review. J. Ind. Eng. Chem. 2015, 29, 1-11. [CrossRef]

15. Xia, Y.; He, Y.; Chen, C.; Wu, Y.; Chen, J. $\mathrm{MoS}_{2}$ nanosheets modified $\mathrm{SiO}_{2}$ to enhance the anticorrosive and mechanical performance of epoxy coating. Prog. Org. Coat. 2019, 132, 316-327. [CrossRef]

16. Li, B.; Mao, B.; Wang, X.; He, T. Fabrication and frictional wear property of bamboo-like SiC nanowires reinforced SiC coating. Surf. Coat. Technol. 2020, 389, 125647. [CrossRef]

17. Sekhavat Pour, Z.; Ghaemy, M.; Bordbar, S.; Karimi-Maleh, H. Effects of surface treatment of $\mathrm{TiO}_{2}$ nanoparticles on the adhesion and anticorrosion properties of the epoxy coating on mild steel using electrochemical technique. Prog. Org. Coat. 2018, 119, 99-108. [CrossRef]

18. Oliveira, J.D.; Rocha, R.C.; Galdino, A.G.D.S. Effect of $\mathrm{Al}_{2} \mathrm{O}_{3}$ particles on the adhesion, wear, and corrosion performance of epoxy coatings for protection of umbilical cables accessories for subsea oil and gas production systems. J. Mater. Res. Technol. 2019, 8, 1729-1736. [CrossRef]

19. Hu, C.; Li, Y.; Kong, Y.; Ding, Y. Preparation of poly(o-toluidine)/nano ZnO/epoxy composite coating and evaluation of its corrosion resistance properties. Synth. Met. 2016, 214, 62-70. [CrossRef]

20. Wu, R.; Zhou, K.; Yue, C.Y.; Wei, J.; Pan, Y. Recent progress in synthesis, properties and potential applications of SiC nanomaterials. Prog. Mater. Sci. 2015, 72, 1-60. [CrossRef]

21. Fan, J.Y.; Wu, X.L.; Chu, P.K. Low-dimensional SiC nanostructures: Fabrication, luminescence, and electrical properties. Prog. Mater. Sci. 2006, 51, 983-1031. [CrossRef]

22. Yang, Y.; Lai, L.Y.; Ding, G.F.; Chen, T. SiC nanowire-based SU-8 with enhanced mechanical properties for MEMS structural layer design. Nanotechnol. Precis. Eng. 2020, 2, 169-176. [CrossRef]

23. Zhang, W.; Yamashita, S.; Kita, H. Progress in tribological research of SiC ceramics in unlubricated sliding-A review. Mater. Des. 2020, 190, 108528. [CrossRef]

24. Rahaman, M.N.; Boiteux, Y.; Dejonghe, L.C. Surface characterization of silicon nitride and silicon carbide powders. Am. Ceram. Soc. Bull. 1985, 65, 171-176.

25. Naeimirad, M.; Zadhoush, A.; Neisiany, R.E. Fabrication and characterization of silicon carbide/epoxy nanocomposite using silicon carbide nanowhisker and nanoparticle reinforcements. J. Compos. Mater. 2016, 50, 435-446. [CrossRef]

26. Kychkin, A.A.; Anan'Eva, E.S.; Tankova, K.I.; Kychkin, A.K.; Tuisov, A.G. Influence of ultrafine silicon carbide powders on the properties of epoxy resin. Struct. Integr. 2019, 20, 185-189. [CrossRef]

27. Nigrawal, A.; Buddi, T.; Rana, R.S.; Purohit, R. Development of epoxy/nano SiC composites and their mechanical studies. Mater. Today Proc. 2019, 18, 4384-4391. [CrossRef]

28. Iijima, M.; Kamiya, H. Surface modification of silicon carbide nanoparticles by azo radical initiators. J. Phys. Chem. C 2008, 112, 397-398. [CrossRef]

29. Huang, L.Y.; Lu, C.X.; Wang, F.; Dong, X.Z. Piezoelectric property of PVDF/graphene composite films using $1 \mathrm{H}, 1 \mathrm{H}, 2 \mathrm{H}, 2 \mathrm{H}-\mathrm{Perfluorooctyltriethoxysilane} \mathrm{as} \mathrm{a} \mathrm{modifying} \mathrm{agent.} \mathrm{J.} \mathrm{Alloys} \mathrm{Compd.} \mathrm{2016,} \mathrm{688,} \mathrm{885-892.} \mathrm{[CrossRef]}$

30. Shang, X.; Zhu, Y.; Li, Z. Surface modification of silicon carbide with silane coupling agent and hexadecyl iodiele. Appl. Surf. Sci. 2017, 394, 169-177. [CrossRef]

31. Esmeryan, K.D.; Mchale, G.; Trabi, C.L.; Geraldi, N.R.; Newton, M.I. Manipulated wettability of a superhydrophobic quartz crystal microbalance through electrowetting. J. Phys. D Appl. Phys. 2013, 46, 345307. [CrossRef]

32. Liu, H.D.; Zhang, H.; Pang, J.; Ning, Y.J.; Jia, F.; Yuan, W.F.; Gu, B.; Zhang, Q.P. Superhydrophobic property of epoxy resin coating modified with octadecylamine and $\mathrm{SiO}_{2}$ nanoparticles. Mater. Lett. 2019, 247, $204-207$. [CrossRef] 
33. Usman, B.J.; Scenini, F.; Curioni, M. The effect of exposure conditions on performance evaluation of post-treated anodic oxides on an aerospace aluminium alloy: Comparison between salt spray and immersion testing. Surf. Coat. Technol. 2020, 399, 126157. [CrossRef]

34. Kulkarni, S.A.; Ogale, S.B.; Vijayamohanan, K.P. Tuning the hydrophobic properties of silica particles by surface silanization using mixed self-assembled monolayers. J. Colloid Interface Sci. 2008, 318, 372-379. [CrossRef]

35. Palimi, M.J.; Rostami, M.; Mahdavian, M.; Ramezanzadeh, B. Surface modification of $\mathrm{Cr}_{2} \mathrm{O}_{3}$ nanoparticles with 3-amino propyl trimethoxy silane (APTMS). Part 1: Studying the mechanical properties of polyurethane/ $\mathrm{Cr}_{2} \mathrm{O}_{3}$ nanocomposites. Prog. Org. Coat. 2014, 77, 1663-1673. [CrossRef]

36. Palimi, M.J.; Rostami, M.; Mahdavian, M.; Ramezanzadeh, B. Surface modification of $\mathrm{Fe}_{2} \mathrm{O}_{3}$ nanoparticles with 3-aminopropyltrimethoxysilane (APTMS): An attempt to investigate surface treatment on surface chemistry and mechanical properties of polyurethane/ $\mathrm{Fe}_{2} \mathrm{O}_{3}$ nanocomposites. Appl. Surf. Sci. 2014, 320, 60-72. [CrossRef]

37. Sabzi, M.; Mirabedini, S.M.; Zohuriaan-Mehr, J.; Atai, M. Surface modification of $\mathrm{TiO}_{2}$ nano-particles with silane coupling agent and investigation of its effect on the properties of polyurethane composite coating. Prog. Org. Coat. 2009, 65, 222-228. [CrossRef]

38. Lin, J.; Siddiqui, J.A.; Ottenbrite, R.M. Surface modification of inorganic oxide particles with Silane coupling agent and organic dyes. Polym. Adv. Technol. 2001, 12, 285-292. [CrossRef]

39. Nechanicky, M.A.; Chew, K.W.; Sellinger, A.; Laine, R.M. $\alpha$-Silicon carbide/ $\beta$-silicon carbide particulate composites via polymer infiltration and pyrolysis (PIP) processing using polymethylsilane. J. Am. Ceram. Soc. 2000, 20, 441-451. [CrossRef]

40. Chew, K.W.; Sellinger, A.; Laine, R.M. Processing of aluminum, nitride/silicon carbide composites via polymer infiltration and pyrolysis of polymethylsilane, a precursor to stoichiometric SiC. J. Am. Ceram. Soc. 1999, 82, 857-866. [CrossRef]

41. Iwata, H.P.; Lindefelt, U.; Öberg, S.; Briddon, P.R. Stacking faults in silicon carbide. Physica B 2003, 340, 165-170. [CrossRef]

42. Choi, H.-J.; Lee, J.-G. Stacking faults in silicon carbide whiskers. Ceram. Int. 2000, 26, 7-12. [CrossRef]

43. Yuan, H.; Qi, F.; Zhao, N.; Wan, P.; Zhang, B.; Xiong, H.; Liao, B.; Ouyang, X. Graphene oxide decorated with titanium nanoparticles to reinforce the anti-corrosion performance of epoxy coating. Coatings 2020, 10, 129. [CrossRef]

44. Georgakilas, V.; Bourlinos, A.B.; Zboril, R.; Trapalis, C. Synthesis, Characterization and aspects of superhydrophobic functionalized carbon nanotubes. Chem. Mater. 2008, 20, 2884-2886. [CrossRef]

45. Shi, G.; Zhang, M.Q.; Rong, M.Z.; Wetzel, B.; Friedrich, K. Friction and wear of low nanometer $\mathrm{Si}_{3} \mathrm{~N}_{4}$ filled epoxy composites. Wear 2003, 254, 784-796. [CrossRef]

46. Mishchenko, L.; Hatton, B.; Bahadur, V.; Taylor, J.A.; Krupenkin, T.; Aizenberg, J. Design of ice-free nanostructured surfaces based on repulsion of impacting water droplets. ACS Nano 2010, 4, 7699-7707. [CrossRef] [PubMed]

47. Lu, S.; Li, S.; Yu, J.; Yuan, Z.; Qi, B. Epoxy nanocomposites filled with thermotropic liquid crystalline epoxy grafted graphene oxide. RSC Adv. 2013, 3, 8915-8923. [CrossRef]

48. Bortz, D.R.; Heras, E.G.; Martin-Gullon, I. Impressive fatigue life and fracture toughness improvements in graphene oxide/epoxy composites. Macromolecules 2012, 45, 238-245. [CrossRef]

49. Pourhashem, S.; Ghasemy, E.; Rashidi, A.; Vaezi, M.R. Corrosion protection properties of novel epoxy nanocomposite coatings containing silane functionalized graphene quantum dots. J. Alloys Compd. 2018, 731, 1112-1118. [CrossRef]

50. Xia, W.; Xue, H.; Wang, J.; Wang, T.; Song, L.; Guo, H.; Fan, X.; Gong, H.; He, J. Functionlized graphene serving as free radical scavenger and corrosion protection in gamma-irradiated epoxy composites. Carbon 2016, 101, 315-323. [CrossRef]

51. Cano, E.; Lafuente, D.; Bastidas, D.M. Use of EIS for the evaluation of the protective properties of coatings for metallic cultural heritage: A review. J. Solid State Electrochem. 2010, 14, 381-391. [CrossRef]

52. Tian, W.; Meng, F.; Liu, L.; Li, Y.; Wang, F. The failure behaviour of a commercial highly pigmented epoxy coating under marine alternating hydrostatic pressure. Prog. Org. Coat. 2015, 82, 101-112. [CrossRef]

53. Zhi, D.; Wang, H.; Jiang, D.; Parki, I.P.; Zhang, X. Reactive silica nanoparticles turn epoxy coating from hydrophilic to super-robust superhydrophobic. RSC Adv. 2019, 9, 12547-12554. [CrossRef] 
54. Xiong, H.; Qi, F.; Zhao, N.; Yuan, H.; Wan, P.Y.; Liao, B.; Ouyang, X.P. Effect of organically modified sepiolite as inorganic nanofiller on the anti-corrosion resistance of epoxy coating. Mater. Lett. 2019, 260, 126941. [CrossRef]

55. Xu, Y.S.H.; Gao, D.; Dong, Q.; Li, M.H.; Liu, A.; Wang, X.C.; Wang, S.F.; Liu, Q. Anticorrosive behavior of epoxy coating modified with hydrophobic nano-silica on phosphatized carbon steel. Prog. Org. Coat. 2021, 151, 106051. [CrossRef]

Publisher's Note: MDPI stays neutral with regard to jurisdictional claims in published maps and institutional affiliations.

(C) 2020 by the authors. Licensee MDPI, Basel, Switzerland. This article is an open access article distributed under the terms and conditions of the Creative Commons Attribution (CC BY) license (http://creativecommons.org/licenses/by/4.0/). 